\title{
Biomimetically Synthesized Aqueous Ferrofluids Having Antibacterial and Anticancer Properties
}

\author{
Lubna Sheikh ${ }^{1,2}$, Richa Vohra ${ }^{3}$, Anita Kamra Verma ${ }^{3}$, Suprabha Nayar ${ }^{1 *}$ \\ ${ }^{1}$ CSIR-National Metallurgical Laboratory, Jamshedpur, India \\ ${ }^{2} \mathrm{CSIR}$-Indian Institute of Chemical Biology, Kolkata, India \\ ${ }^{3}$ Nanobiotech Lab, Kirori Mal College, University of Delhi, Delhi, India \\ Email: suprabha.nayar@gmail.com
}

Received 19 February 2015; accepted 10 March 2015; published 17 March 2015

Copyright @ 2015 by authors and Scientific Research Publishing Inc.

This work is licensed under the Creative Commons Attribution International License (CC BY). http://creativecommons.org/licenses/by/4.0/

(c) (i)

\section{Abstract}

Synthesis of functional iron oxide nanoparticles, well dispersed in aqueous fluids still remains a challenge as its stability requires a delicate balance between electrostatic and magnetic interactions. Templated synthesis using biomolecules is useful because the biomolecules have their unique arrangement in aqueous systems that enhance stability, commonly called "biomimetic synthesis". We have developed a one-pot in-situ, low energy process for the synthesis of highly monodispersed, Collagen Functionalized Ferrofluids (CFF) as a templating agent in an aqueous medium. The nanoparticles so obtained were characterized by X-ray diffraction (XRD), dynamic light scattering (DLS), Fourier transform infrared spectroscopy (FTIR). The antibacterial activity in terms of minimum inhibitory concentration (MIC), minimum bactericidal concentration (MBC) and growth inhibition has been assessed against gram positive, Staphylococcus aureus, ATCC 13709 (native strain) and in Escherichia coli, DH5 $\alpha$ gram negative bacteria. The cytotoxicity of the CFFs on cancer cell lines human embryonic kidney (HEK), breast adenocarcinoma (MCF-7) and Ehrlich ascitic carcinoma (EAC) have also been investigated. CFFs indicated variable MIC and MBC values against $S$. aureus and $E$. coli being minimum for $1.5 \%$ CFF (MIC:23.43 $\mu \mathrm{g} / \mathrm{ml}$ and $93.75 \mu \mathrm{g} / \mathrm{ml}$ and MBC: $46.87 \mu \mathrm{g} / \mathrm{ml}$ and $187.5 \mu \mathrm{g} / \mathrm{ml}$ ). The observed cytotoxicity in mammalian cells indicated the susceptibility of MCF-7 breast cancer cells when compared to HEK cells.

\section{Keywords}

Collagen Functionalized Ferrofluids (CFFs), Antibacterial, Biomimetics, Cytotoxicity, Anti-Cancer Activity

\footnotetext{
${ }^{*}$ Corresponding author.
}

How to cite this paper: Sheikh, L., Vohra, R., Verma, A.K. and Nayar, S. (2015) Biomimetically Synthesized Aqueous Ferrofluids Having Antibacterial and Anticancer Properties. Materials Sciences and Applications, 6, 242-250. 


\section{Introduction}

Ferrofluids (FF) have been widely used in biomedical research because of its unique properties and ease of administration. FF consists of iron oxide nanoparticles (IONPs) of size 5 - $10 \mathrm{~nm}$ coated with a surfactant dispersed in a carrier fluid, which if aqueous, favors biomedical applications. Functionalized IONPs are in great demand, as they contain inherent anchoring groups for biofunctionalization, can incorporate fluorescent dyes, and have shown low cellular toxicity [1]-[4]. IONPs are multifunctional as they can be maneuvered by remote magnetic fields, can be heated up using a remote, alternating magnetic field and can be exploited to selectively kill cancer cells by magnetic hyperthermia. Functionalized IONPs can be specifically designed to reach the desired organs within the body, while carrying and off loading the payload directly to the target site.

Thermal decomposition, microemulsion and co precipitation methods are commonly used to prepare IONPs. Chemical coprecipitation is preferred as nanopartcles of high-purity/stoichiometry [5] can be produced. Restricting the size to below that of the single domain size ensures super paramagnetic property, this coupled with chemical stability [6] make IONPs extremely promising for biomedical applications. Inorganic core of iron oxide, such as magnetite $\left(\mathrm{Fe}_{3} \mathrm{O}_{4}\right)$, and maghemite $\left(\gamma-\mathrm{Fe}_{2} \mathrm{O}_{3}\right)$ coated with a polymer such as chitosan [7] dextran [8], poly (ethylene glycol) (PEG) [9] and poly(ethylenimine) (PEI) [10], have been reported earlier. Another method for forming monolayers is by self-assembly ligand exchange for noble metal nanoparticles, where, the thiol groups attach strongly to the surface. This approach is achievable for iron oxide nanoparticles using $\alpha$-cyclodextrin or polymers [11]-[13]. Since these layers are often not covalently bonded to the surface, high ionic strength or extreme $\mathrm{pH}$ conditions might alter their interaction. Reactivity of silanol molecules, produced by the hydrolyzation of alkoxy silane has been observed [14] [15]. We report surface functionalized Collagen ferrofluids (CFFs) in aqueous fluids for enhancing biocompatibility and stability in biological systems.

\section{Materials and Methods}

Anhydrous ferric chloride $\left(\mathrm{FeCl}_{3}\right)$ and Liquor ammonia (30\% v/v) was purchased from MERCK, Mumbai, India; hydrated ferrous chloride $\left(\mathrm{FeCl}_{2} \cdot 4 \mathrm{H}_{2} \mathrm{O}\right)$ from LOBA CHEMIE, Mumbai, India; Collagen, (3-(4,5-dimethyathiazol-2-yl)-2,5-diphenyltetrazolium bromide (MTT), Dimethyl sulphoxide (DMSO), Sodium bicarbonate, Penicillin, Streptomycin and HEPES (Hydroxy ethyl piperazineethanesulphonic acid) were purchased from Sigma-Aldrich St Louis, (USA). RPMI-1640 was obtained from Gibco laboratories, Foetal calf Serum (FCS) was purchased from Hyclone, Logan, UT. All the chemicals were of analytical grade and used without further purification. Double distilled water was used throughout the experiment. 2:1 $\mathrm{M}$ ferric $\left(\mathrm{Fe}^{3+}\right)$ and ferrous $\left(\mathrm{Fe}^{2+}\right)$ chloride stock solution was prepared in double distilled water and filtered to remove impurities, if any. Iron stock solution $2 \mathrm{M}: 1 \mathrm{M}$ was further diluted to get a final concentration of $0.5 \mathrm{M}: 0.25 \mathrm{M}$ in the synthesis mixture. Three concentrations of Collagen Ferrofluid (CFF) were prepared using 0.5\%, 1.5\%, 2.5\% collagen. The system was left to equilibrate for 24 hrs and then ammonia was added slowly at $\sim 60^{\circ} \mathrm{C}$ till the pH reached 10.5 to oxidize the iron ions to oxide. At this point the heating was stopped while stirring was continued for another 24 hrs. The sample was further centrifuged for 30 minutes at about 8000 r.p.m, withstanding which, the fluid, was assumed to be stable. The supernatant or the Biomimetic Ferrofluids was used throughout the experiment and some part of this fluid was dried at $60^{\circ} \mathrm{C}$ in a vacuum oven for 24 hrs and then ground with mortar pessel for other characterizations like XRD, FT-IR etc.

\subsection{Dynamic Laser Light Scattering (DLS)}

The size of nanoparticles were measured by Zetasizer Nano ZS (Malvern, UK) based on DLS. Briefly, nanoparticles were suspended in distilled water at a concentration of $0.5 \%, 1.5 \%$ and $2.5 \%$. Size measurements were performed at $25^{\circ} \mathrm{C}$ with $173^{\circ}$ scattering angle and the mean hydrodynamic diameters were determined by cumulative analysis [16]. Further details about DLS and data analysis can be found elsewhere [17] [18].

\subsection{Fourier Transform Infrared Spectroscopy (FT-IR)}

FT-IR spectra of the $\mathrm{Fe}_{3} \mathrm{O}_{4}$ nanoparticles and CFF were recorded over the range of $400-4000 \mathrm{~cm}^{-1}$ by diamond ATR (Agilent Technologies).

\subsection{Anti-Bacterial Activity (Agar Disc Assay)}

Disc diffusion method (Kirbey-Bauer method) was used as per our previously published protocol [19] [20]. 
Briefly, Luria agar [LA] (3.5\%) and Agar agar (0.8\%) were prepared and autoclaved. Hard agar (LA) was poured into the petri-plates and was allowed to solidify on cooling. The bacterial inoculum was prepared in Agar agar at a ratio of 1:100. The soft agar was poured carefully on the solidified agar plates ( $2 \mathrm{ml} /$ petri-plate). The sterile paper discs were dipped in the respective samples, including the controls (positive and negative), and these were placed meticulously on pre-marked areas. The plates were incubated overnight at $37^{\circ} \mathrm{C}$, for the formation of zones around the discs that confirmed the antibacterial activity, if any of the various samples. The results were further compared with the standard Gentamycin sulphate $\left(1 \times 10^{-3} \mu \mathrm{g} / \mathrm{ml}\right)$ disc that was used as positive control.

\subsection{Determination of MIC and MBC Values}

Turbidimetric method was used to determine the minimum inhibitory concentration (MIC) and minimum bactericidal concentration (MBC) of CFF [21]. Briefly, $5.0 \mathrm{~mL}$ of Muller-Hinton broth (MHB, Difco, England) were prepared in test tubes and then autoclaved. Three concentrations of CFF, $0.5 \%, 1.5 \%, 2.5 \%$ were added to these tubes separately and serially diluted further so that next test tube contains half the concentration of previous one. The experimental tubes were then inoculated with $50 \mu \mathrm{L}$ of $S$. aureus or E. coli bacterial culture and were allowed to incubate at $37^{\circ} \mathrm{C}$ for $18 \mathrm{~h}$. The tubes were then observed for signs of turbidity. The lowest concentration of CFF that inhibited the growth of bacteria was considered as MIC while the least concentration at which there was no sign of growth was referred to MBC and thus bacterial growth was observed for various CFF concentrations.

\subsection{Cell Culture and Cytotoxicity}

Human embryonic kidney cell line, HEK and breast cancer cell line: MCF-7 (American Type Culture Collection, Rockville, MD) to establish the in-vitro cytotoxicity, as per previously published protocols [22]. Confluent flasks were subcultured and maintained at $37^{\circ} \mathrm{C}$ and $5 \% \mathrm{CO}_{2}$ in Dulbecco's modified Eagle's medium (Sigma, St. Louis, MO) under a humidified atmosphere (95\%). The media were supplemented with $10 \%$ foetal bovine serum, $50 \mu \mathrm{g} / \mathrm{mL}$ of penicillin and $50 \mu \mathrm{g} / \mathrm{mL}$ of streptomycin. $5 \times 10^{3}$ cells/well of HEK and MCF-7 cells were plated in 96-well plates. Three concentrations of CFF i.e. $0.5 \%, 1.5 \%$ and $2.5 \%$ were added to the cells and incubated over 72 hours. After the requisite time of incubation, $20 \mu$ of MTT (3-(4,5-dimethylthiazol-2-yl)-2, 5diphenyltetrazolium bromide; ( $5 \mathrm{mg} / \mathrm{mL}$ stock) was added per well. The formazan crystals formed post 4 hours of incubation were dissloved in a known amount of dimethyl sulfoxide. Readings were done in triplicates in a (Synergy HT, Biotek, USA) using a $540 \mathrm{~nm}$ filter. Percentage viability of the cells was calculated as the ratio of mean absorbance, $\mathrm{A}$, of triplicate readings with respect to mean absorbance of control wells:

$$
\text { Cell Viability }=\frac{\left(A_{\text {control }}-A_{\text {sample }}\right)}{A_{\text {control }}} \times 100
$$

\section{Results}

\subsection{XRD}

The XRD spectrum of three different ferrofliuds i.e. 0.5\%, 1.5\% and 2.5\% CFF shown in Figure 1, was indexed with the reference pattern of magnetite (JCPDS Card No. 75-1610) and maghemite (JCPDS Card No. 24-0081). Characteristic peaks corresponding to Bragg planes (220), (311), (400), (511) and (440) confirm the presence of both these iron oxide phases and the broadening of XRD peaks shows the nanocrystalline nature of the synthesized particles. Differentiation of $\mathrm{Fe}_{3} \mathrm{O}_{4}$ and $\gamma-\mathrm{Fe}_{2} \mathrm{O}_{3}$ from normal X-ray diffractograms is extremely difficult due to the similarity of their crystal structure and lattice parameter. The average crystallite size corresponding to the (311) peak estimated from the Scherrer's equation was $23 \mathrm{~nm}, 19 \mathrm{~nm}$ and $15 \mathrm{~nm}$ respectively. The difference of size can be explained by a concept that as the concentration of the collagen is increased, denser the matrix becomes smaller the size of the particles, apparent in our system with the least size of the synthesized nanoparticles incase of $2.5 \%$ and maximum in $0.5 \%$.

\subsection{FT-IR}

The results of IR Spectroscopy (Figure 2) indicate that all the three samples retained the triple helical structure 


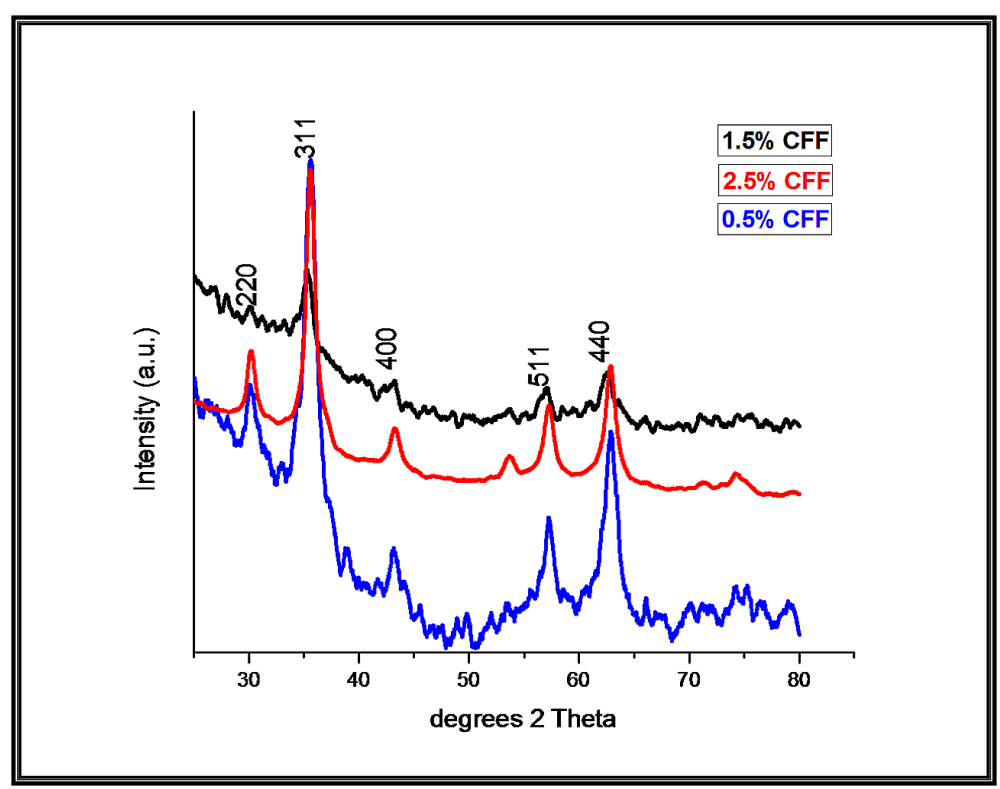

Figure 1. XRD spectra of the synthesized CFFs.

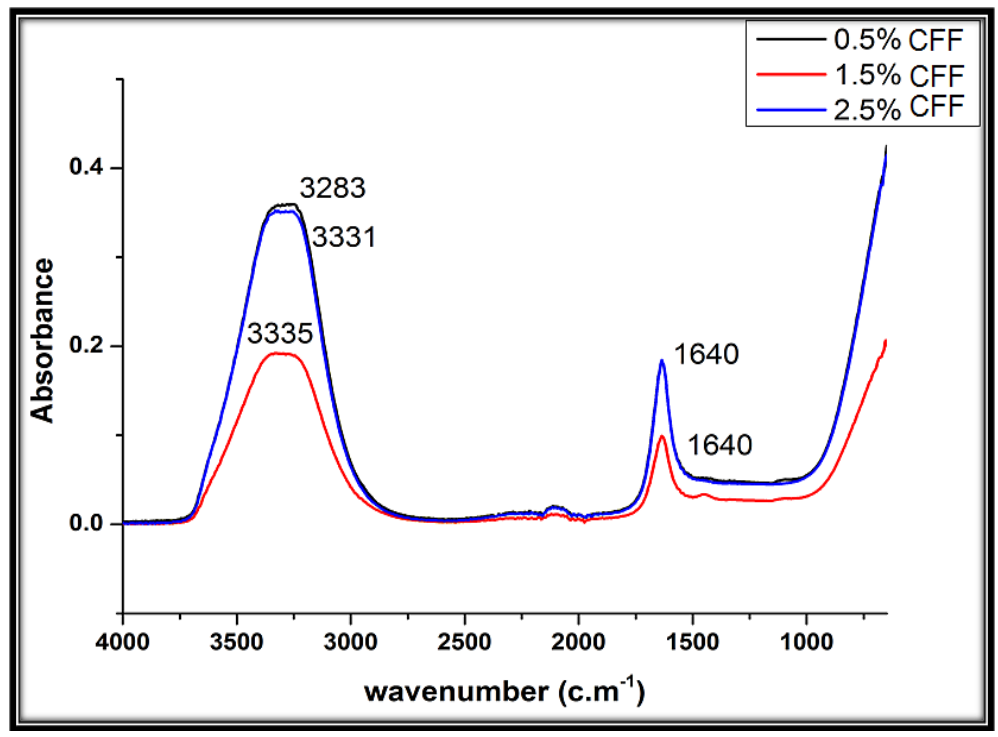

Figure 2. FT-IR spectra of CFFs.

of native collagen and the characteristic Amide II (N-H) bending vibrations were observed at around $1550 \mathrm{~cm}-1$, a minor peak, not marked in the spectra. Similarly Amide I ( $\mathrm{C}=\mathrm{O}$ stretching) and Amide A (N-H stretching) signatures were also seen respectively at 1632 - 1664 and $3318-3350 \mathrm{~cm}^{-1}$. Moreover a shift (to higher frequencies) in the Amide A band indicates the crosslinking and this trend is observed in all samples. This shift may stem from coordinate or H-bonding interactions of the amide nitrogen. It seems likely that this is because of the increase in the concentration of collagen which in turn effect the nucleation and growth of the IONPs. All the three samples follow the same trend and shows a precise binding of collagen to the iron oxide.

\subsection{DLS}

DLS of the three fluids synthesized, the $1.5 \%$ CFF is the most monodispersed (Table 1); it has the lowest poly dispersity index (PDI), though its size is the same as that of $0.5 \%$. The zeta potential is inversely proportional to the hydrodynamic diameter, and the $1.5 \%$ CFF seems to have the optimal properties needed for both anti- 
Table 1. Characteristics of the three fluids as per dynamic light scattering data.

\begin{tabular}{cccc}
\hline & \multicolumn{3}{c}{ DLS } \\
CFF & PDI & SIZE (Dnm) & Zeta meV \\
\cline { 2 - 4 } & 0.542 & 271.9 & -26.1 \\
$1.5 \%$ & 0.248 & 276.3 & -16.6 \\
$2.5 \%$ & 0.475 & 361.0 & -10.7 \\
\hline
\end{tabular}

bacterial and cytotoxic effect, as seen below.

\subsection{Antimicrobial and Cytotoxicity Studies}

The histogram in Figure 3(a) and Figure 3(b) shows the effect of tested fluids on the gram positive and gram negative bacteria respectively. The agar diffusion is shown in Figure 4. Table 2 summarizes the bactericidal activity of CFF loaded specimens on gram positive and gram negative bacteria. The tested Ferrofluids also showed different effects on cell viability (Figure 5), dependent on the cell lines tested. This data demonstrates that the CFF showed negligible cytotoxicity in 24 hrs both in EAC and MCF-7 cell lines. Dose-dependent cytotoxicity was observed in all three concentrations, but $1.5 \%$ CFF showed maximum cytotoxicity at $0.75 \mathrm{mg} / \mathrm{ml}(65 \%)$ and minimal at $0.09 \mathrm{mg} / \mathrm{ml}(35 \%)$ at $72 \mathrm{hrs}$ in EAC cell line. Approximately, $60 \%$ cytotoxicity was observed at 1.5 $\mathrm{mg} / \mathrm{ml}$ in MCF-7 cell lines. 0.5\% exhibited moderate cytotoxicity in both the cell lines, but surprisingly 2.5\% CFF showed reduced cytotoxicity when compared to the other cancer cell lines. MCF-7 cells were most susceptible to CFFs at all concentrations.

\section{Discussion}

A unique feature of IONPs, exploited for drug delivery is their applicability for both alternatives i.e. magnetic properties and antibody attachment [23]. Superparamagnetism acts as an activation mechanism because once the external magnetic field is eliminated, the magnetization disappears, and hence the possible embolization of the capillary vessels can be avoided [24]. Generally, the coating agents that are physically adsorbed either by hydrogen binding or electrostatic interactions do not show high stability in comparison to coating agents which are chemically adsorbed. Polymers are most frequently used for coatings to make biocompatible iron oxide suspensions [25] such as derivatives of dextran [26] [27] (dextran, carboxymethylated dextran, carboxydextran), starch, polyethyleneglycol poly(lactic acid), arabinogalactan, glycosaminoglycan, siloxane, sulphonated styrene-divinylbenzene, poly( $\varepsilon$-caprolactone) or polyalkyl-cyanoacrylate [28]-[30]. Many surface-modifying agents have been explored to increase stability of magnetic nanoparticles. For biological applications, nanoparticles must be highly stable in aqueous ionic solutions at physiological $\mathrm{pH}$. The chance finding of aqueous FFs as anti-bacterial leaves one wondering whether, it is the metallic part which has anti-bacterial and cytotoxicity properties or is it the nano size and structure which is responsible. Compared to silver, a known antimicrobial agent since ancient times has been effective as silver nitrate. Though, nano-silver has now been put to practical use in commonly used items, such as, clothes, electric home appliances, and electronic industry, it has yet not been widely applied in the medical or pharmacological fields. In humans, nano-silver is found to have a significant cytotoxic effect on Peripheral Blood Mononuclear Cell (PBMCs). Upscaling of synthesis of silver nanoparticles is not economically viable but IONPs definitely offer an attractive alternative strategy.

The success of nanoparticles in drug delivery or any other biomedical applications is possible only if their toxicities toward both microbes and mammalian cells are carefully evaluated. Although, many contradictory results have been published about the toxicity of superparamagnetic iron oxide nanoparticles, recently Mahmoudi et al. (2011) [31] reported that the surface coating large influences different cell types and the possible toxic effects vary accordingly [13]. Tartaj et al. (2003) [32] [33] reported that the size, shape, and magnetic dipole moment of the particles may also play a role in in vivo experiments. The one pot biomimetic synthesis i.e. at ambient temperature and pressure and without the use of any harsh chemicals has helped us in making perfectly stable and biocompatible Ferrofluids. We have observed that surface coatings help negate the toxicities and 


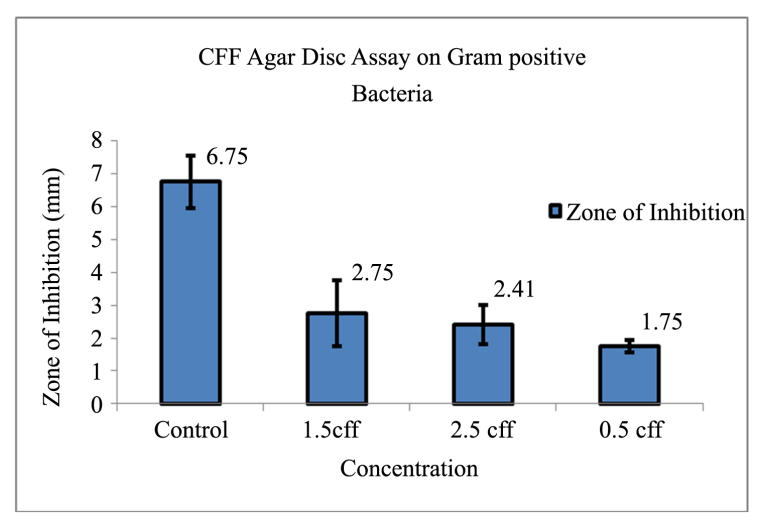

(a)

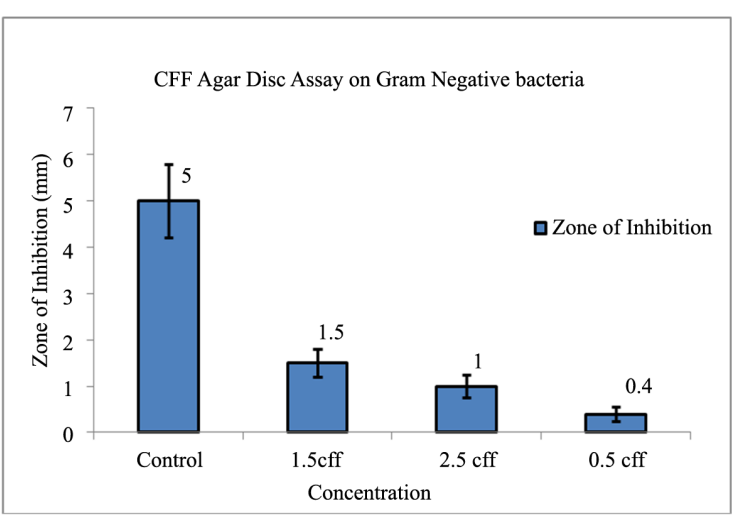

(b)

Figure 3. (a) Antimicrobial activity of CFF drug against gram positive nose bacteria; (b) Antimicrobial activity of CFF drug against gram negative bacteria.

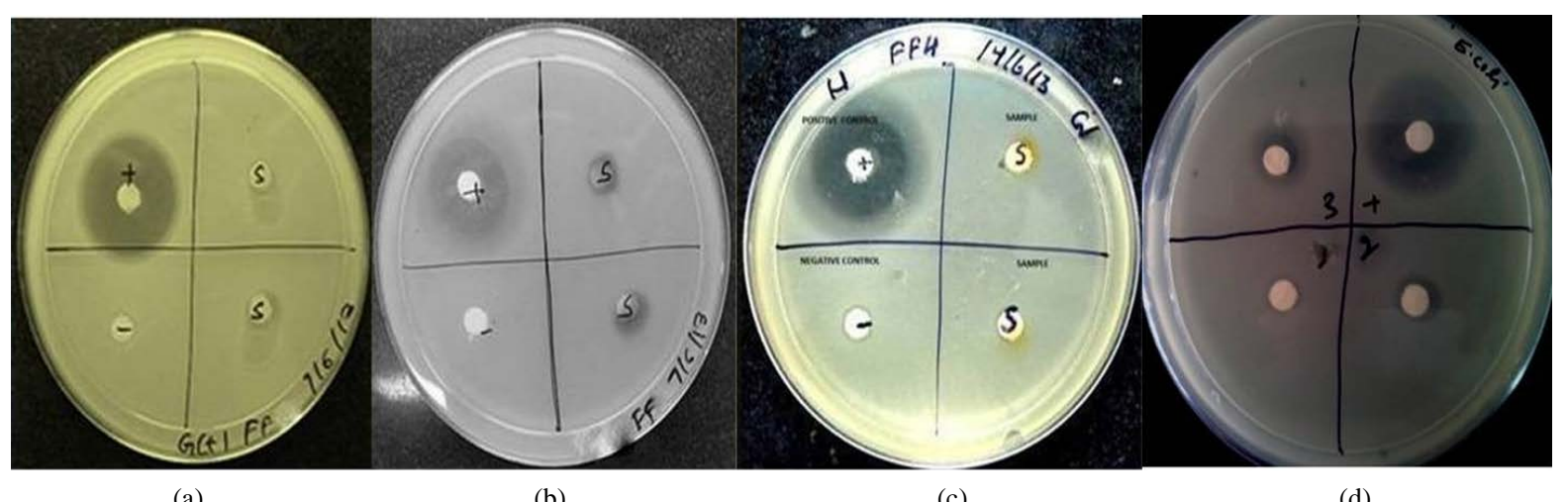

(a)

(b)

(c)

(d)

Figure 4. Analysis of zone of inhibition data where (a) 1.5\% CFF drug showed more zone of inhibition (2.75 mm) as compared to other concentrations, (b) $2.5 \%$ CFF and (c) $0.5 \%$ CFF in gram positive bacteria, (d) showing similar results in gram negative bacteria, more killing in $1.5 \%$ CFF $(1.5 \mathrm{~mm})$ followed by $2.5 \%$ CFF and $0.5 \%$ CFF.

Table 2. Bactericidal activity of CFF loaded specimens on gram positive and gram negative bacteria.

\begin{tabular}{ccccccc}
\hline S. No. & Test organism & $\begin{array}{c}\text { Negative control } \\
(\mathbf{m m})\end{array}$ & $\begin{array}{c}\text { Positive control } \\
(\mathbf{m m})\end{array}$ & $\begin{array}{c}\mathbf{0 . 5 \%} \mathbf{C F F} \\
\mathbf{( m m})\end{array}$ & $\begin{array}{c}\mathbf{1 . 5 \%} \mathbf{C F F} \\
\mathbf{( m m})\end{array}$ & $\begin{array}{c}\mathbf{2 . 5 \%} \mathbf{C F F} \\
(\mathbf{m m})\end{array}$ \\
\hline 1. & $\begin{array}{c}\text { Gram positive } \\
\text { bacteria }\end{array}$ & - & $6.75 \pm 0.8$ & $1.75 \pm 1$ & $2.75 \pm 0.6$ & $2.41 \pm 0.2$ \\
& $\begin{array}{c}\text { Gram negative } \\
\text { bacteria }\end{array}$ & - & $5.0 \pm 0.8$ & $0.4 \pm 0.3$ & $1.5 \pm 0.24$ & $1.0 \pm 0.15$ \\
\hline
\end{tabular}

$(-)=$ No zone of inhibition. Values are given as means \pm SD of three experiments. Positive control (gentamycin, $1 \mathrm{mg} / \mathrm{ml}$ ); negative control (distilled water).

make them biocompatible.

\section{Conclusion}

Biomimetic synthesis of CFFs produces fluids with high dispersion yields and controlled particle size has been achieved with three different collagen concentrations. It is interesting to note that the anti-bacterial and cytotoxic effect on different cancer cells could well be a function of its monodispersity and microstructural arrangement. Collagen, just like it binds calcium ions at regular intervals in natural bone-formation binds the ferrous/ferric ions to form patterned iron oxides. In the case of IONPs in addition to the templating effect, there also is a magnetic interaction and the combined effect of these two interactions is the formation of not only stable ferrofluids but also its anti-bacterial and cytotoxic effects. Such antibacterial properties along with its toxicity to cancer cell 

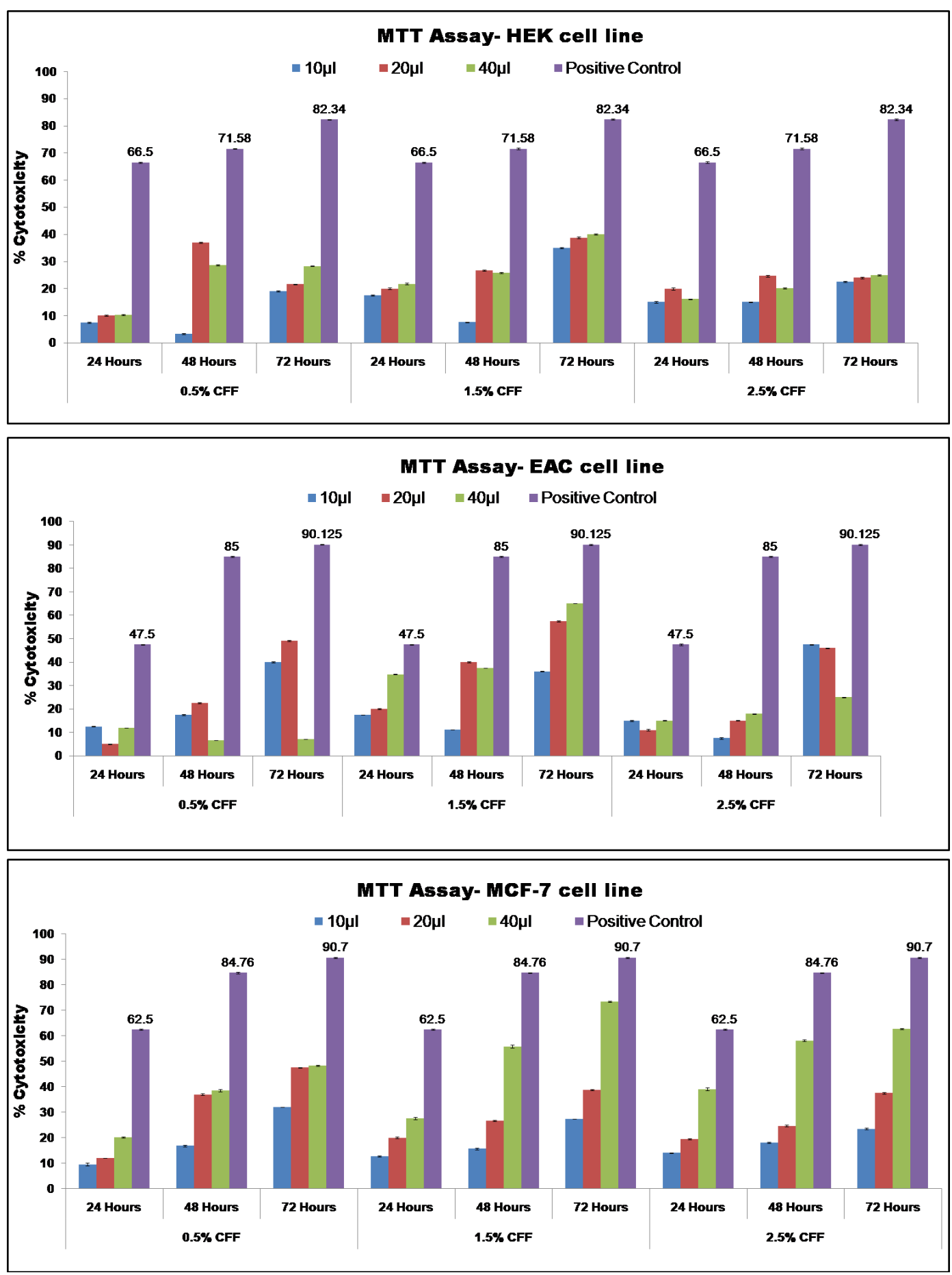

Figure 5. Dose and time dependant cytotoxicity of CFFs on EAC, HEK and MCF-7 cell lines.

lines pose great promise for nanomaterials stabilized with organic molecules to be used in bio-medical applications.

\section{Acknowledgements}

The authors would like to thank CSIR-Minstry of Science and Technology, OLP-0230 and DST for their financial support for research. 


\section{References}

[1] Vijay, K., Varadan, L.C. and Xie, J.N. (2008) Nanomedicine: Design and Applications of Magnetic Nanomaterials, Nanosensors and Nanosystems. Wiley, Hoboken.

[2] Arruebo, M., Fernández-Pacheco, R., Ibarra, M.R. and Santamaría, J. (2007) Magnetic Nanoparticles for Drug Delivery. Nanotoday, 2, 22-32. http://dx.doi.org/10.1016/S1748-0132(07)70084-1

[3] Kumar C.S.S.R. and Mohammad, F. (2011) Magnetic Nanomaterials for Hyperthermia-Based Therapy and Controlled Drug Delivery. Advanced Drug Delivery Reviews, 63, 789-808. http://dx.doi.org/10.1016/j.addr.2011.03.008

[4] Gubin, S.P. (2009) Magnetic Nanoparticles. Wiley-VCH, Weinheim. http://dx.doi.org/10.1002/9783527627561

[5] Chen, S., Feng, J., Guo, X., Hong, J. and Ding, W. (2005) One-Step Wet Chemistry for Preparation of Magnetite Nanorods. Materials Letters, 59, 985-988. http://dx.doi.org/10.1016/j.matlet.2004.11.043

[6] Nidhin, M., Indumathy, R., Sreeram, K.J. and Nair, B.U. (2008) Synthesis of Iron Oxide Nanoparticles of Narrow Size Distribution on Polysaccharide Templates. Bulletin of Materials Science, 31, 93-96. http://dx.doi.org/10.1007/s12034-008-0016-2

[7] Li, G.Y., Jiang, Y., Huang, K., Ding, P. and Chen, J. (2008) Preparation and Properties of MagneticFe $\mathrm{O}_{4}-\mathrm{Chitosan}$ Nanoparticles. Journal of Alloys and Compounds, 466, 451-456. http://dx.doi.org/10.1016/j.jallcom.2007.11.100

[8] Hong, R.Y., Feng, B., Chen, L.L., Liu, G.H., Li, H.Z., Zheng, Y. and We, D.G. (2008) Synthesis, Characterization and MRI Application of Dextran-Coated $\mathrm{Fe}_{3} \mathrm{O}_{4}$ Magnetic Nanoparticles. Biochemical Engineering Journal, 42, 290-300. http://dx.doi.org/10.1016/j.bej.2008.07.009

[9] Mukhopadhyay, A., Joshi, N., Chattopadhyay, K. and De, G.A. (2012) Facile Synthesis of PEG-Coated Magnetite $\left(\mathrm{Fe}_{3} \mathrm{O}_{4}\right)$ Nanoparticles and their Prevention of the Reduction of Cytochrome C. ACS Applied Materials \& Interfaces, 4, 142-149. http://dx.doi.org/10.1021/am201166m

[10] Yiu, H.H., McBain, S.C., Lethbridge, Z.A., Lees, M.R. and Dobson, J. (2010) Preparation and Characterization of Polyethylenimine-Coated $\mathrm{Fe}_{3} \mathrm{O}_{4}$-MCM-48 Nanocomposite Particles as a Novel Agent for Magnet-Assisted Transfection. Journal of Biomedical Materials Research Part A, 92, 386-392. http://dx.doi.org/10.1002/jbm.a.32363

[11] Fauconnier, N., Pons, J., Roger, J. and Bee, A. (1997) Thiolation of Maghemite Nanoparticles by Dimercaptosuccinic Acid. Journal of Colloid and Interface Science, 194, 427-433. http://dx.doi.org/10.1006/jcis.1997.5125

[12] Wang, Y., Wong, J.F., Teng, X., Lin, X.Z. and Yang, H. (2003) Pulling Nanoparticles into Water: Phase Transfer of Oleic Acid Stabilized Monodisperse Nanoparticles into Aqueous Solutions of $\alpha$-Cyclodextrin. Nano Letters, 3, 15551559. http://dx.doi.org/10.1021/nl034731j

[13] Park, J.W., Bae, K.H., Kim, C. and Park, T.G. (2011) Clustered Magnetite Nanocrystals Cross-Linked with PEI for Efficient siRNA Delivery. Biomacromolecules, 12, 457-465. http://dx.doi.org/10.1021/bm101244j

[14] Soderholm, K.J.M. and Shang, S.W. (1993) Molecular Orientation of Silane at the Surface of Colloidal Silica. Journal of Dental Research, 72, 1050-1054. http://dx.doi.org/10.1177/00220345930720061001

[15] Zhang, Y., Kohler, N. and Zhang, M. (2002) Surface Modification of Superparamagnetic Magnetite Nanoparticles and Their Intracellular Uptake. Biomaterials, 23, 1553-1561. http://dx.doi.org/10.1016/S0142-9612(01)00267-8

[16] Bohren, C.F. and Huffman, D.R. (1983) Absorption and Scattering of Light by Small Particles. John Wiley and Sons, New York, 483-489.

[17] Cummins, H.Z. and Pike, E.R. (1974) Photon Correlation and Light Beating Spectroscopy. Plenum, New York.

[18] Berne, B.J. and Pecora, R. (1976) Dynamic Light Scattering. Wiley, New York.

[19] Ip, M., Lui, S.L., Poon, V.K., Lung, I. and Burd, A. (2006) Antimicrobial Activities of Silver Dressings: An in Vitro Comparison. Journal of Medical Microbiology, 55, 59-63.

[20] Mohanty, B., Verma, A.K., Claesson, P. and Bohidar, H.B. (2007) Physical and Anti-Microbial Characteristics of Carbon Nanoparticles Prepared from Lamp Soot. Nanotechnology, 18, Article ID: 445102.

[21] Tyagi, A., Agarwal, S., Leekha, A. and Verma, A.K. (2014) Effect of Mass and Aspect Heterogeneity of Chitosan Nanoparticles on Bactericidal Activity. International Journal of Advanced Research, 2, 357-367.

[22] Verma, A.K., Sachin, K., Saxena, A. and Bohodar, H.B. (2005) Release Kinetics from Bio Polymeric Nanoparticles Encapsulating Protein Synthesis Inhibitor-Cycloheximide, for Possible Therapeutic Applications. Current Pharmaceutical Biotechnology, 6, 121-130. http://dx.doi.org/10.2174/1389201053642349

[23] Mahmoudi, M., Hosseinkhani, H., Hosseinkhani, M., Boutry, S., Simchi, A., Shane Journeay, W.S., Subramani, K. and Laurent, S. (2011) Magnetic Resonance Imaging Tracking of Stem Cells in Vivo Using Iron Oxide Nanoparticles as a Tool for the Advancement of Clinical Regenerative Medicine. Chemical Reviews, 111, 253-280. http://dx.doi.org/10.1021/cr1001832

[24] Gupta, A.K. and Gupta, M. (2005) Synthesis and Surface Engineering of Iron Oxide Nanoparticles for Biomedical Ap- 
plications. Biomaterials, 26, 3995-4021. http://dx.doi.org/10.1016/j.biomaterials.2004.10.012

[25] Beets-Tan, R.G.H., Van Engelshoven, J.M.A. and Greve, J.W.M. (1998) Hepatic Adenoma and Focal Nodular Hyperplasia: MR Findings with Superparamagnetic Iron Oxide-Enhanced MRI. Clinical Imaging, 22, 211-215. http://dx.doi.org/10.1016/S0899-7071(97)00117-4

[26] Mahmoudi, M., Simchi, A., Imani, M., Milani, A.S. and Stroeve, P. (2008) Optimal Design and Characterization of Superparamagnetic Iron Oxide Nanoparticles Coated with Polyvinyl Alcohol for Targeted Delivery and Imaging. Journal of Physical Chemistry B, 112, 14470-14481. http://dx.doi.org/10.1021/jp803016n

[27] Boyer, C., Whittaker, M.R., Bulmus, V., Liu, J. and Davis, T.P. (2010) The Design and Utility of Polymer-Stabilized Iron-Oxide Nanoparticles for Nanomedicine Applications. NPG Asia Materials, 2, 23-30. http://dx.doi.org/10.1038/asiamat.2010.6

[28] Hong, R.Y., Feng, B., Chen, L.L., Liu, G.H., Li, H.Z., Zheng, Y. and Wei, D.G. (2008) Synthesis, Characterization and MRI Application of Dextran-Coated $\mathrm{Fe}_{3} \mathrm{O}_{4}$ Magnetic Nanoparticles. Biochemical Engineering Journal, 42, $290-300$. http://dx.doi.org/10.1016/j.bej.2008.07.009

[29] Saboktakin, M.R., Tabatabaie, R.M., Maharramov, A. and Ramazanov, M.A. (2010) A Synthetic Macromolecule as MRI Detectable Drug Carriers: Aminodextran-Coated Iron Oxide Nanoparticles. Carbohydrate Polymers, 80, 695-698. http://dx.doi.org/10.1016/j.carbpol.2009.11.051

[30] Corot, C., Robert, P., Idee, J.M. and Port, M. (2006) Recent Advances in Iron Oxide Nanocrystal Technology for Medical Imaging. Advanced Drug Delivery Reviews, 58, 1471-504. http://dx.doi.org/10.1016/j.addr.2006.09.013

[31] Mahmoudi, M., Laurent, S., Shokrgozar, M.A. and Hosseinkhani, M. (2011) Toxicity Evaluations of Superparamagnetic Iron Oxide Nanoparticles: Cell "Vision” versus Physicochemical Properties of Nanoparticles. ACS Nano, 5, 72637276. http://dx.doi.org/10.1021/nn2021088

[32] Tartaj, P., Morales, M.D.P., Veintemillas-Verdaguer, S., Gonzalez-Carreno, T. and Serna, C.J. (2003) The Preparation of Magnetic Nanoparticles for Applications in Biomedicine. Journal of Physics D: Applied Physics, 36, 182-197. http://dx.doi.org/10.1088/0022-3727/36/13/202

[33] Sheikh, L., Mahto, N. and Nayar, S. (2015) In Situ Synthesis of Hydroxyapatite Nanocomposites Using Iron Oxide Nanofluids at Ambient Conditions. Journal of Materials Science: Materials in Medicine, 26, 5393. 